This is the accepted version of an article published as Wilson, M., Johnston, H. and Walker, L. (2020) "It was like an animal in pain': Institutional thoughtlessness and experiences of bereavement in prison', Criminology \& Criminal Justice. https://

doi.org/10.1177/1748895820930755

\title{
'It was like an animal in pain': Institutional thoughtlessness and experiences of bereavement in prison
}

\begin{abstract}
Using the concept of institutional thoughtlessness (Crawley, 2005; Crawley and Sparks, 2005a, 2005b), this article examines a range of issues embedded within daily prison life which have a detrimental effect upon the lives of those bereaved during a prison sentence. Drawing on in-depth qualitative research undertaken with bereaved prisoners, staff members and volunteers at a male prison in the North of England, the article explores how individual and institutional goals compete, compounding bereavement experiences and the management of grief. Findings demonstrate the tension between the policies and protocols prisons are tasked to follow, and unintended consequences for the individually bereaved. This paper illuminates the need for far greater understanding of bereavement in the prison population and explores how a universal life experience can be particularly debilitating within the prison setting with the potential to exacerbate what is often cumulative loss amongst prisoners.
\end{abstract}

(total word count 9511 words)

\section{Keywords}

Bereavement, prisoner, excessive grief, prison regime, prison staff

\section{Marion Wilson}

University of Hull, UK

\section{Helen Johnston}

University of Hull, UK

\section{Liz Walker}

University of Hull, UK

\section{Corresponding author:}

Marion Wilson, Department of Criminology and Sociology, University of Hull, Cottingham Road, Hull, HU6 7RX.

\section{Email: marionwilson.hull@gmail.com}

Telephone +44(0)1482 346311

\section{Author biographies/ORCIDs}

Marion Wilson (ORCiD 0000-0002-8167-3316) recently obtained a PhD in 
Social Policy and is currently employed by Cruse Bereavement Care. Her research interests centre on bereavement and its effects upon prisoners.

Helen Johnston (ORCiD 0000-0003-3922-766X) is Professor of Criminology and Co-director of the Centre for Criminology \& Criminal Justice at the University of Hull.

Liz Walker (ORCiD 0000-0002-1652-5800) is Professor of Health and Social Work Research at the University of Hull. She has long-standing research interests in the sociology of chronic illness, death and dying with an emphasis on end-of-life care.

\section{Acknowledgements}

The authors thank the MoJ/NOMS for approving the research and 'HMP North of England' for allowing access to the prison, to undertake the research in partial fulfilment of a PhD in Social Policy.

\section{Declaration of Conflicting Interests}

The authors declared no potential conflicts of interest with respect to the research, authorship, and/or publication of this article.

\section{Funding}

The first author received a PhD scholarship from the University of Hull.

\section{Introduction}

This article explores the neglectful handling of bereaved individuals within the largely overlooked setting of the prison institution (Corcoran, 2018). It examines male prisoners' experiences of bereavement by drawing on in-depth qualitative research in one male prison in the North of England. Using semi-structured interviews, small focus groups and participant observation, the findings obtained strongly suggest that the adult prison regime interferes with the grieving process, caused by reduced autonomy in choosing how to manage the symptoms of grief (Vaswani, 2018). The context of being imprisoned results in grief being disenfranchised (Ferszt, 2002) - the position of incurring a death that cannot be openly acknowledged, publicly mourned, or socially supported (Doka, 1989). Accordingly, prisoners are at heightened risk of a more excessive grief reaction than the normal population (Durcan, 2008). While prisoners are not deliberately denied a basic service, institutional thoughtlessness (acts of omission) (Crawley, 2005; Crawley and Sparks, 2005a, 2005b) can occur through rigid adherence to institutional practices.

Death is often recognised as the ultimate loss (Read and Santatzoglou, 2018). The majority of the population experience a normal grief reaction when natural 
loss is experienced, but estimates suggest that approximately 5-11 percent experience what is termed complex grief (Lundorff et al, 2017; Nielsen et al, 2017). The percentage increases slightly if loss is unexpected and traumatic (Kristensen et al, 2012), stigmatised (Valentine et al, 2016), or involves the death of a child (Lichtenthal et al, 2015). People living in low income households in the community experience complicated grief symptoms more frequently than people benefiting from higher incomes (Newsom et al, 2019). Further, prisoners are recognised as being at more risk than the general population in experiencing a range of psychosocial losses (Vaswani, 2015). Examples include low socio-economic status (Friestad, 2010), differing forms of abuse and fractured family relationships, childhood abandonment by a parent through imprisonment, or being placed in care (Leach et al, 2008; Vaswani, 2015). Other loss may pertain to employment (Olson and McEwen, 2004), immigration, long-term illness (physical/mental) and disability (Parkes, 2006). In addition to Sykes' (1958) five pains of imprisonment encountered during incarceration (loss of liberty, goods and services, heterosexual relationships, autonomy and security), loss of future, status and stability are also keenly felt (Vaswani, 2015). Thus, a significant bereavement experienced in prison must be recognised in the context of the cumulative effect of additional losses encountered over the lifecourse. The principle aim of this paper is to demonstrate how aspects of the prison regime and associated protocol directly affect and compound the grieving process amongst the prison population.

\section{The prison population and bereavement}

It has been widely recognised that men's prisons are hyper-masculine environments (Crewe, 2012, Jewkes, 2005). An empowered masculine presence rather than a submissive stance is displayed when uncertainty and perceived risk are present (Ricciardelli et al, 2015). Tears are not culturally acceptable and the overall inmate code of behaviour is antithetical to the grieving process (Schetky, 1998). This has the damaging effect of disenfranchising grief (Hendry, 2009) and placing prisoners at risk of complicated grief (Harner et al, 2011). Unresolved grief is exceedingly common in prison populations (Leach et al, 2008), but is likely to be concealed by disruptive behaviours (Schetky, 1998) and often receives little attention.

Although incarceration can amplify the grieving process, prison protocol and security take precedence over any ritual behaviours considered vital at a time of, and following, a significant loss (Aday and Wahidin, 2016). Thus, institutional barriers hamper the healthy processing of grief. Due to incarceration prisoners are unable to spend time with the deceased prior to death (Ferszt, 2002). There is often frustration due to inability to speak to dying 
relatives on the telephone (Schetky, 1998). Traditional rituals prisoners can be prevented from experiencing include organising and involvement in funeral and memorial services (Harner et al, 2011) and visiting the grave (Ferszt, 2002).

Prisoners are expected to return to prison routines promptly, with little opportunity to mourn the loss (Aday and Wahidin, 2016). Further, spontaneous forms of grief expression may attract disciplinary action during confinement. Resisting engagement with grief support and with few private spaces in which to grieve, prisoners frequently suspend the grieving process until release (Ferszt, 2002; Harner et al, 2011).

There is a paucity of empirical research relating to adult male, bereaved prisoners (Hendry, 2009; Leach et al, 2008), despite males making up the overwhelming majority of the prison population (Gov.UK, 2019). Consequently, literature pertaining to female prisoners, young offenders and male prisoners in Australasia and the USA has been drawn upon. Bereavement is recognised as one of the most stressful life events for adults (Holmes and Rahe, 1967; Lee, 2015) and young people (Yeaworth et al, 1980). Young offenders experience a higher rate of parental death, multiple and traumatic deaths than their adolescent counterparts (Finlay and Jones, 2000; Vaswani, 2014).

Bereavement also intensifies existing problems; becoming a contributory factor in the custodial sentencing of young offenders (Finlay and Jones, 2000).

Despite experiencing emotional isolation and feelings of detachment directly attributed to their bereavement experiences, young offenders routinely fail to accept professional bereavement support (Vaswani, 2014). They frequently resort to drugs to cope with grief symptoms, experience depression, anxiety and suicidal thoughts (Finlay and Jones, 2000). Investigating the reasons for selfinflicted deaths in custody of 18-24 year-olds, the Prison Reform Trust in its submission to the Harris Review (2015) identified sudden and unexpected deaths of significant family members as being a contributory factor. Life events such as bereavement cause high levels of distress (Ferszt, 2002). When such a situation occurs during the first few weeks of imprisonment it has the effect of exposing the already vulnerable person to additional risk of suicide (Liebling and Ludlow, 2016).

This paper will draw on prisoners', staff members' and volunteers' experiences of dealing with bereavement in the prison setting. It will highlight the numerous tensions between the protocols of the prison, the macho inmate culture and the extent to which prisoners manage or fail to manage the healthy processing of their grief.

\section{Methodology}

Ethical approval to conduct the study was obtained from the University of Hull 
Ethics Committee and the MoJ/NOMS (project identification number 189619). The philosophical underpinnings of social justice research advocate the use of constructivism (Charmaz, 2014). A range of foundational considerations determined the choice of qualitative approach (see Creswell and Poth, 2018), with the decision eventually being taken to use adapted grounded theory (Glaser and Strauss, 1967). Contrasting with narrative research and case studies which concentrate more on chronological life storying and extensive description of a few individuals in order to interpret patterns of meaning respectively, the chosen approach allowed a much higher number of prisoners and those directly responsible for them to get their voices heard to aid theory generation. Evolving data identified processes and interactions, with theory being grounded in the unifying and competing perspectives from the field, organised by means of NVivo 11 software. Semi-structured interviews, small focus groups and field observation were undertaken between March and August 2017 in a male, category C prison in the North of England. Observation aided acquisition of a broader understanding of the research setting. Convenience and snowball sampling methods were utilised to facilitate recruitment for interviews. Purposive sampling required that a prisoner should meet the following criteria:

- He had been at HMP North of England longer than four weeks.

- A significant bereavement occurred earlier than one month previously.

- Release or transfer was not anticipated within one month.

- Prison records provided no current indication of a risk of self-harm or suicide.

The sampling strategy for staff members and volunteers was that their work roles needed to encompass either direct or indirect involvement with bereaved prisoners. Thirteen females and 13 males $(\mathrm{N}=26)$ participated. One-to-one interviews took place with: a governor (head of Functioning and Residential), four chaplains, a male and female prison officer (PO) working on the wings, PO working in the segregation unit, family liaison officer/supervising officer (FLO/ SO), senior clinician working for the mental health team, drugs and alcohol rehabilitation lead, nurse, lead information technology tutor, and a Cruse Bereavement Care volunteer. Paired interviews were organised with two custodial managers and two members of the Independent Monitoring Board. Finally, two small focus groups were conducted comprising four probation workers and four psychologists. Interviews were recorded digitally, each lasting approximately one hour, and transcribed verbatim. A short topic guide was prepared for the prisoners and those working in the prison. The prisoners were 
asked what bereavements they had experienced in prison and prior to imprisonment. They were also invited to speak about how they reacted due to being bereaved. Additional open questions were used, allowing each participant to choose the direction of their interview and aspects they felt comfortable sharing. Consequently, the topics covered were not consistent across the narrative accounts. Participants were anonymised using pseudonyms. No incentives were offered.

Themes in this article address the negative impact of institutional processes on prisoners' bereavement experiences and the management of grief symptoms. Brief details concerning the participants and their bereavements are provided:

\begin{tabular}{|l|r|}
\hline Ages of the prisoner participants & 8 \\
\hline $21-30$ & 8 \\
$31-40$ & 4 \\
$41-50$ & 1 \\
$51-60$ & 2 \\
\hline $61-65$ & 23 \\
\hline Ethnicity & \\
\hline White British & 19 \\
Asian/Asian British/Pakistani & 3 \\
Irish & 1 \\
\hline
\end{tabular}

Table 1 Age and ethnicity of the prisoner participants

Significant bereavements experienced over the lifecourse include (but are not restricted to): 
Mother/step mother

Father/step father

Partner

Grandmother

Grandfather

Brother

Sister

Child

Abortion

Best friend

Significant cousin

Significant aunt/uncle

Significant friend

Other (including supporting a dying work colleague immediately following an industrial accident, suicide in prison of 'associates', a fire resulting in the deaths of an aunt, uncle and cousins).

Caused death to another (murder/RTA).

Of the above deaths, sudden and traumatic losses include (but are not restricted to): Hanging/drug-related

Alcohol related

Jumping from bridge

Murder

RTA

Of the 104 deaths, significant losses notified which took place during imprisonment include (but are not restricted to): 


\begin{tabular}{|l|r|}
\hline Mother/step mother & 7 \\
Father/step-father & 5 \\
Grandmother & 5 \\
Grandfather & 2 \\
Brother & 5 \\
Sister & 2 \\
Best friend & 4 \\
Significant cousin & 3 \\
Significant aunt/uncle & 3 \\
Significant friend & 5 \\
\hline
\end{tabular}

Table 2 Breakdown of important deaths. Other meaningful deaths occurred, however, these were not discussed due to time limitations.

\section{Findings}

The study's findings confirm that a multiplicity of factors can combine to make the effects of bereavement particularly difficult to confront while serving a prison sentence. These have been themed, taking a logical course through the experience of bereavement immediately prior to imprisonment and while detained in a carceral setting.

\section{The effects of bereavement and coping}

To set the scene, the data revealed that while struggling to cope with cumulative loss, grief 'overload' tipped the balance for at least eight men, resulting in offending for which they were sentenced. Five men described imprisonment having been fortuitous at the time. In their view, this helped to prevent further adverse grief responses.

(Dale) It probably did me good coming to jail ... Just to sort myself out.

Despite this comment Dale used cognitive avoidance to cope:

Every time I thought of her I pushed it to t' side, sort of thing. Do you know, pphhsshh, and I occupied my mind in some other way. ... I still do it to this day, you know, owt' just to change me thought process.

When bad news was received in prison, protracted numbness was a very common reaction. Wayne's brother died approximately nine months earlier. Wayne stated:

I'm still feeling numb now. 
There was cognitive inability to accept such news straightforwardly and avoidant strategies were adopted. Seventeen of the 23 participants had used drugs, self-harm, alcohol or violent behaviour to cope with bereavement preand/or during imprisonment. The remaining six participants had used distraction techniques including avoiding speaking of their bereavements to prevent intimidation by staff members and inmates, and to help them cope. Lewis stated:

Obviously, there's a lot of drugs in the prison, yeh? And the first thing I was thinking of was to numb this feeling, you know?

Although avoidance was a common strategy, Kieran explained how emotions nevertheless erupted:

l've always kept everything in. I used to hit walls and stuff like that. That would get my anger out.

Danny turned to violence in prison and actively intended to end his own life:

... they'll say something about your Mam and unfortunately he didn't know what had gone on with me Mam. ... I ended up fighting with the lad. I got brought up fighting. ... I got a slip under me door, telling me that I'm due for release in a couple of months. And, erm, I set fire to me cell and tried to hang meself. ... me Mum wouldn't have wanted that for me. ... she knew what she meant to me.

Kirsty (FLO/SO) explained how staff members take precautionary measures in response to maladaptive coping:

We make notes of lads that we know that have had significant bereavements in the family. And that might be a trigger for them to selfharm. ... Quite a few lads ... have committed death by dangerous driving, so it's sometimes the date they were sentenced or the date that this happened. ... there's quite a lot of triggers.

There was a general unwillingness to reach out for support due to the hypermasculine inmate culture (Crewe, 2016; Jewkes, 2005) which affected emotional coping. Newsom et al's (2017) study into the effectiveness of bereavement counselling through a community-based organisation in Scotland attracted a ratio of 79 percent of females and 21 percent males; this being representative of the counselling organisation's usual client base. Mitch's stance was:

Nobody else can do it apart from myself ... I wouldn't seek out support anyway if it were offered to me. 
Unless prison workers were regarded as possessing jail craft - whereby staff 'maintain order and have functioning working relationships with prisoners' (Peacock et al, 2017: 3) - they were often mistrusted and participants felt unable to unburden their grief symptoms with them.

Problem-focused coping is recognised as an integral aspect of the grieving process (Stroebe and Schut, 1999). However, this was not evident due to an inability to address bereavement-related problems away from family life and the local community. Examples include attending to family finances, taking on new household tasks and being involved in the practical care of other family members.

The Chaplaincy team provided valuable assistance for those who proactively sought pastoral, practical, spiritual or religious support, however, such support may not have been quite so readily taken up by those with little or no faith. Finally, five men began displaying 'act-desistance' behaviours (Nugent and Schinkel, 2016). They distanced themselves from an anti-social past and gained a newfound sense of stability (Weaver and McNeill, 2014). These effects arose due to the men gaining sufficient courage to begin safely confronting grief stressors, with assistance from trustworthy others with whom they were able to identify.

\section{Official recognition of a dying or deceased family member}

Staff members adhere to a policy framework (MoJ, 2019) which outlines the procedures to be followed when a prisoner's close family member is dying or has died. A close relative is defined as a:

... spouse/life partner (ie someone with whom the offender was living as a couple in an established relationship immediately prior to imprisonment), parent, child, brother, sister (including half- or step- brothers and sisters), or a person who has been in loco parentis to an offender, or to whom the offender has been in loco parentis (MoJ, 2019: 30).

Governors may consider other close caring relationships within an extended family; it being the prisoner's responsibility to establish the strength of that relationship. Also, a terminally ill relative must want the prisoner to visit.

Seven prisoner participants found the death of a grandparent particularly difficult to deal with. Jason received permission to attend his grandmother's funeral:

She was my everything, yeh. I felt like l'd lost half meself, basically. Grandparents had often made considerable contributions in helping with child 
rearing, yet authenticating proof often proved difficult. Lydia, the Roman Catholic (RC) chaplain, explained:

If they've said, "Well, l've lived with them," if we can't find, or OMU [Offender Management Unit] can't find in their files any mention of them living with the grandparents, then it's a "No" straightaway.

Common procedure is for the Chaplaincy to receive notification that a relative is near to death, or has died. This information has to be verified by a reliable external source before staff are notified and the news is broken to the inmate.

\section{Verifying information and breaking bad news}

Various accounts revealed a range of regime-related problems centring around timing and external organisations being fearful of breaching confidentiality.

The chaplains stated that sometimes fictitious information was received, so they were required to verify notifications. They were observed working tenaciously to authenticate information at the earliest opportunity although there could be delays, depending when and to whom the message was relayed. Lydia (RC chaplain), described herself as being like, "a dog with a bone." Recalling a typical request, she continued:

"We just need to know because the lad's not going to see his father before he dies if you don't give the go-ahead. If you tell me he's going to get well again, I'll take your word for that. That's absolutely fine, but I do really need to know."

Charlie, the Free Church (FC) chaplain, outlined an ongoing situation whereby an inmate was due for release in four days' time. He had worked late the previous night, trying to obtain information on the prisoner's brother. Charlie contacted a hospice and was notified his sibling's death wasn't imminent. The next morning the hospice informed Chaplaincy the sibling had died. Charlie broke the news:

At that point he went absolutely ballistic. ... "Get out of my f-ing space. You didn't let me go and see my brother, ...."

Stress, worry and anxiety increase when the prison wall becomes an obstacle between a prisoner and family members (Scott and Codd, 2010). The chaplains indicated that special visits can only be granted if a relative is hours, or at most a couple of days, away from death. This can leave the prisoner in an extremely distressed state, resulting in negative pent-up emotions being released to the detriment of self, other occupants or workers.

Staff members of external organisations can interpret the General Data 
Protection Regulation (2018) standards (Gov.UK, 2018) in a way that protects the rights of dying family members' sensitive data to the detriment of prisoners anxiously awaiting news. Therefore, transfer of vital information was often delayed when the concept of time was at a premium. Delayed information exchange can occur due to barriers being actively raised by individual employees, or they may emerge more passively due to structural and institutional arrangements (Auschra, 2018).

The delivery of bad news can be an uncomfortable experience for both giver and recipient in any event (Aein and Delaram, 2014), but the distinctiveness of the prison environment and culture definitively shapes how bad news is received. Prisoners frequently responded to bad news, poorly, resulting in Michael (Governor grade) reporting:

Verbal aggression, err times where prisoners will damage furniture. They'll probably hurt themselves ... It's important that yes, we manage the crisis there and then, but it's also about the days after and the weeks after when we have to still consider that they might be in crisis as well.

Chaplaincy staff record details on the p-NOMIS (Prison National Offender Management Information System), in the Wing Observation book and Chaplaincy team journal. There can be a hiatus when bad news is waiting to be delivered due to work patterns and staffing issues. For one prisoner, Gavin, this resulted in an unexpected and enforced swapping of familial roles between imprisoned father and teenage daughter. His mother died on a Friday. Gavin's older sister had left details with the prison but the paperwork was lying on a desk and no-one acted upon it in time. He rang his daughter on the Sunday, recommending she should visit her grandmother because she was, "ready to pass." However, his daughter had to be the bearer of the news:

It killed me ... Me youngest daughter's 16 years old. For her to have to tell her Dad that his Mam's died, it's a bit wrong. ... For leaving it two, fucking, three days before I had to find out from me daughter. When they all knew what was going on. Obviously, it wasn't Mr ...'s fault, you know. ... If l'd have snapped, fucking 'ell, l'd have just got meself more jail.

This example indicates that poor institutional processes can impact the prisoner and in this instance, an adolescent. Gavin, struggling to retain his integrity, recognised the implications of openly demonstrating how this situation had affected him. With such an act of misconduct potentially increasing the length of one's sentence (Bottoms, 1999), true thoughts and feelings had to be suppressed. Gavin's former reactions to death - snapping - had been 
superseded by maintaining control and demonstrating emotional stoicism within this masculine-dominated environment (Hendry, 2009).

\section{Special temporary release}

Clearance having been obtained - assuming the loss is recognised by the MoJ the necessary practical arrangements begin to visit a dying relative or attend a funeral. The Chaplaincy confirmed approximately 80 percent of the men there were allowed special temporary release to visit a dying relative and/or attend a funeral. Lydia (RC chaplain) explained:

Their freedom's been taken away from them ... usually if it's a very close relative they will get out. But there ... may be a risk to security and they're not going to let them go. Or the police may say, "You're not to let that person go to that funeral. There's going to be trouble." Sometimes you get big families and it's just a 'no-no', really. ... We can't always give the reasons.

If it could be arranged and if they were willing, the remaining men could spend a short time in the Chapel with a chaplain. Lydia (RC chaplain) was careful not to raise hopes in terms of prisoners receiving permission for special temporary release. Instead, she emphasised the need to raise an element of doubt, to protect both the inmate and the prison's decision-making process. She recounted witnessing a prisoner's expression of pain as a result of refusal:

One lad asked me on the wing last week and I never would have told him like that. But ... I couldn't lie to him when I knew that he'd been turned down [for temporary release]. I explained, 'I'm really sorry.' ... He was just glaring. He went back into his cell, shut the door and let out this loud scream. It was like an animal in pain. It was like the pain coming out. ... He was given a phone call and he was heart-broken. ... I think it's harder to deal with, you know, when you see them and it just doesn't touch the surface, really.

The following example refers to promises not being fulfilled by representatives of the criminal justice system, producing intense and prolonged suffering and feelings of helplessness. Having spent many years in prison, Les was declined permission much earlier in his sentence to visit his mother who had enduring health problems before she died in another part of the UK, despite being granted verbal permission by a judge he respected. Probation staff later put forward evidence to prevent any visits. He stated this affected him detrimentally over the years and clearly had been a source of ongoing bitterness towards "the system": 
l'd not seen her $4 \frac{1}{2}$ years before she passed. I was promised on two occasions that l'd definitely see her because she was too ill to travel.

Not only is a prisoner affected when permission is not granted for temporary release, but little consideration may be afforded to the dying relative concerning associated stress, anxiety or other health implications. Institutional decisionmaking is bound up in time-sensitive challenges when based upon prognostication of dying relatives. Prognostic estimates of survival are commonly based upon one of two formats: temporal (how long) or probabilistic (how likely) (Chu et al, 2020). Predicting needs rather than exact prognostication (Gold Standards Framework Centre, 2011) become more germane, such as organising release to visit the dying prior to their decline in cognitive functioning (Williams et al, 2011). Similarly, the effects of depression, feelings of regret and unpreparedness for the death (Wright et al, 2008) should be factored in to decision-making when former prisoners' visits have been unproductive, or following a non-event.

\section{Funeral attendance}

Public rituals 'confer transcendental significance and meaning' and provide a framework in which to grieve and a place to express emotion (Doka, 2002: 135). However, external rituals can be denied or poorly organised. Continuing with accounts received from Mitch, the focus moves onto his involvement in family mourning rituals. While there is institutional recognition of the importance of attending a family funeral, the way this is handled can help or hinder the grieving process. Aside from coping with a family death, unique, regime-related stressors are also present on the day of a funeral. Protocol has to be adhered to outside prison and its effects may also colour the memories of other mourners. The following examples contrast poor with meaningful experiences and memories. Prior to arriving at HMP North of England Mitch was located at the nearest local prison. He was granted permission to attend his deceased sister's funeral from that establishment. He continued:

I started like, getting irate and stressed out ... they knew about the circumstances. ... I go down to the reception hoping that my suit's hung up and when I get down there it's all just still slung in a box. (Voice becomes anxious.) l'd asked them if they could hang it up .... They hadn't bothered. Oh, it was a bit of a nightmare really. I was just fretting all the way there ..., ten minutes late ... to the funeral. ... we'd already put applications in for me to be put on a long chain, you know, to carry my sister ... But they didn't tell me [the application had been refused] 'til I got into the taxi and I was on my way there. ... I thought, 'It's a bad enough 
situation being late and ... then my mum getting upset because I can't carry her [deceased sister].' . .. I thought these issues had all been resolved and my mum should have been notified. ... I felt like I was letting [deceased sister] down that I couldn't ... carry her to her final resting place. ... I went out of the back entrance of the church then and met all the family and literally I was allowed about five minutes and they bundled me back into the taxi, and back to [the prison].

Notwithstanding being given permission to read his sister's eulogy, although he was restrained, the remaining examples above describe poor working practices, resulting in additional stress. Four men described stressful and anxietyprovoking events when attending funerals from prison, directly relatable to prison protocol. Prison management needs to be delivered within an ethical framework, and the question should always be posed, "Is what we are doing right?" (Coyle and Fair, 2018: 14). This is one obvious example of institutional thoughtlessness (Crawley, 2005; Crawley and Sparks, 2005a, 2005b). Statutory authorities derive legitimacy in some measure by 'being seen to act in defence of the wronged', and regarding the prisoner as one of the 'undeserving bereaved' (Corcoran, 2018: 90). Having been transferred to HMP North of England, Mitch was permitted to attend his brother's funeral:

... they have been very, very, very helpful, yes. ... straightaway they were there and got everything in place. They were a bit more friendly when I went out for ... [deceased brother]'s funeral ....

Mitch was required to write three eulogies following the deaths of his siblings and his best friend, which were read at the various services. Although feeling closer to his best friend than his siblings, he was not permitted to attend that funeral, nor that of his cousin, due to institutional protocol. Mitch's account suggests the burden of cumulative loss (including the loss of life for which he had been sentenced) could have been compounded by the effects of imprisonment and the way he had been let down by the insensitive response of the staff at the previous prison in respect of his sister's funeral. Eight participants spoke of deceased best friends and close friends being just as important as, or more important than, biologically close family members. This was often due to the fact of imprisonment and lifestyle. Such relationships were not officially recognised and thus became disenfranchised (Doka, 1989).

\section{Use of restraints and the concept of agency}

At the time of the research a risk assessment was carried out ahead of attending a funeral which determined both the number of escorts required (the minimum being two officers) and the wearing of restraints (Section 7 of PSI 
33/2015) (NOMS, 2015: 23). Accounts from participants verified that usual practice was single handcuffing (occasionally using double handcuffs, and one participant was permitted to wear a chain). Woody refused to go out on temporary licence because he feared humiliating his family:

I wasn't going to embarrass 'em with me stood there with handcuffs .... Haseeb (aged 64), a low-risk prisoner, commented:

When you see somebody handcuffed with a big chain and two officers, they automatically assume you've committed a heinous crime. ... a lot of boys here, because of this handcuffing they don't even bother going to any funeral. You know, something has to change within all the prisons to reflect the attitude of the prisoners.

Recognising that a prisoner has 'foregone his claim to the status of a fullfledged, trusted member of society' (Sykes, 1958: 66), the research nevertheless emphasised the fact that wearing handcuffs could dissuade inmates from attending an important funeral due to perceived humiliation and incorrect assumptions made by other mourners. The wearing of restraints when some prisoners arguably do not need to, produces additional stress. While prisoners could take advantage of special temporary release - being an example of a facility available in principle to prisoners (Crawley, 2005) - some men were failing to consider their own grieving process or recognise the importance of social mourning. Although careful assessment is made prior to release on temporary licence, situations can go dramatically awry. Charlie (FC chaplain) recalled the previous day's events when a prisoner had been granted special permission to attend his father's funeral:

... the inmate had turned to an escort and said, pardon my language, "I need a piss." And it was ... just before the actual coffin's going to go through the curtains. So the officers tried to calm him down: "Look, it's your dad's funeral ...." Then he became very, very irate and had to be took out. ... the family were there taking photographs of him kicking off, which just doesn't help anything.

When accompanying Lydia ( $R C$ chaplain) on a visit to the segregation unit as part of participant observation the following day, an officer confirmed to her that upon his return the same prisoner had assaulted two officers, was then restrained and confined. Charlie (FC chaplain) continued:

I think it was probably remorse that he'd had nothing to do with his dad, as such, and all of a sudden now there's a coffin with his dad in it. Any issues ... he can no longer put 'em right. 
This example highlights competing problems of power, order and resistance (Crewe, 2016) and the absolute need to be recognised as an individual (Ugelvik, 2014) who is struggling to come to terms with past pains and losses.

\section{Little acknowledgement of compound loss}

Consideration needs to be given to the occurrences of compounded loss at least 20 of the men divulged as part of their life histories. During a ten-month period, Mitch (aged 23) had to cope with the death of his brother and sister (both alcohol-related), his best friend (hanging, following which his life support machine had to be turned off) and female cousin, with whom he had a strong relationship (hanging). Prior to this his father had died of cancer when Mitch was 17 . His grandmother who had, "pretty much brought me [him] up", died when he was 12. Mitch was imprisoned, having killed a pedestrian due to dangerous driving:

... it was an accident ... Obviously I blame myself for it ... it wasn't intentional. ... he was in the wrong place at the wrong time and so was I.

These background details provide a more informed understanding of the degree of cumulative bereavements which one participant was living with. Other prisoners provided similar examples of death related and non-death related events experienced over the lifecourse, recognised as a continuum of losses (Read and Santatzoglou, 2018). Additional psychosocial losses reported following bereavement included loss of accommodation and a permanent address, sentimental/symbolic [deceased] loved ones' possessions, and family relationships. Moreover, individuals causing loss of life to loved ones can become both perpetrators and victims. Becoming bereaved and convicted simultaneously are not mutually exclusive conditions (Corcoran, 2018).

\section{Lack of support while on licence}

Although individuals released from prison on licence may be recognised as more integrated members of society than prisoners, due consideration needs to be paid to men who may struggle with difficult grief symptoms upon release, especially if the impact of such loss has not been fully considered during confinement. Sam, aged 24, was serving a sentence in a different prison before his current sentence. During the earlier sentence he had to endure the deaths of his mother and brother (coping with six significant deaths and the deaths of three friends in total, in six years). His previous partner had revoked her promise to continue being a support for him and allowing access to his child. This situation caused further loss of social support. Sam also had a brother who, he explained, was a "repeat offender". While struggling to cope with his 
mother's and brother's deaths, Sam was released on licence and living in a hostel. He was excluded from his familiar locality as a condition of his licence, (stating he had used threatening behaviour towards his deceased brother's girlfriend, whom he indirectly blamed for the death). He recalled:

I had nothing, I had no-one. ... in a town l'd never been to in me life. ... I wasn't allowed in [town] where I was brought up. ... where I could have got support. ... it felt like I was getting suffocated, and I couldn't wait to get back to prison. ... they wouldn't let me go see ma family, ... l've just fucked off from t' hostel, ... to see ma family in (town) for two weeks, ... knowing that I were coming back to prison. But I only thought I were coming back to prison for 28 days and I didn't commit no other offence and I handed myself in and kept in contact with Probation. They added 15 days onto my sentence for being unlawfully at large, and they made me serve a full 18 month just for doing that. ... Ma behaviour hasn't really been bad since l've been in prison. ... They have not took into consideration ma losses at all. ... when I told 'em they said they can't imagine how I'm feeling, but l've got to abide by the law. The system doesn't have no compassion at all (firm in his tone). That's what I know, I know that 100 percent.

It is suggested that inequalities fail to look beyond the quantitative, not recognising there is a qualitative aspect to people's experiences of bereavement in socio-economically disadvantaged communities (Scottish Partnership for Palliative Care, 2018). Sam's account infers that little recognition was paid to his recent bereavements upon sentencing, nor how being placed in an unfamiliar environment away from his familiar social support system would detrimentally affect grief adjustment. Alternative attempts to cope in deprived urban areas can result in reaching out to access heroin or its equivalent (Allen, 2007). In an effort to prevent himself from taking an overdose, Sam spoke of "needing" a structure such as the prison so he could manage the effects of grief because he was unable to trust himself. Although a seemingly preferable option, the institution is ostensibly unable to provide the level of compassion needed for successful grief adjustment. Sam's need was for a feeling of safety and containment, not punishment for an inability to cope with cumulative loss.

\section{Prison as a place of safety?}

Sam continued by verbalising concern for his surviving brother and reduced levels of trust in the prison environment as a place of protection:

... I try to help 'im but it just goes in one ear and out of $t$ ' other. Prison 
used to be safe for him but then he comes to prison now and he smokes that spice and he nearly dies in prison ... it's only a matter of time before I've lost him as well.

Kirsty (FLO/SO) provided a broader picture of the damaging influence of spice:

... spice has completely turned everything on its head for self-harm, for near-misses. We have lads that go to the absolute extreme where they will massively self-harm.

With new psychoactive substances (NPS) being of considerable concern in adult male prisons - frequently connected with violent behaviour, debt, organised crime and medical emergencies - prisons are increasingly becoming more unsafe, and particularly for those reporting a mental health problem (HM Chief Inspector of Prisons, 2017). If legal sources of support cannot be accessed, prisoners will find their own way of obtaining relief, especially when trust has been lost in the establishment. As a result, the biopsychosocial implications of drug abuse may send prisoners back out into society in a far worse state.

\section{Staff shortages}

Prisoners, staff and volunteers all identified staff shortages as one of the main reasons for the many shortcomings and barriers in institutional processes experienced by bereaved prisoners. In addition to the failures described above, it also increased feelings of distrust.

Adrian (Segregation PO): I could maybe say, “... Give us five minutes and I'll come back." ... I get stuck with an incident. ... It could turn into hours. And then me shift's finished. ... It makes you feel like you don't care ...

It's a joke, like: "Oh yes, of course you're going to come back!"

Accordingly, 'bad prison work' arises from structural difficulties (Arnold et al, 2007: 478) which are beyond the scope of a worker, no matter how empathic their individual response may be to the prevailing situation. Further, extended periods of cellular confinement due to staff shortages may encourage unhealthy rumination.

Anne (Cruse volunteer) explained the logistical difficulties of providing support:

I saw one chap once, and he obviously needed help and he wanted me to go back, and I couldn't get in for another six weeks. ... they're very short staffed ... They either had a shut-down which they have regularly, or there was only one person in the chaplaincy because one of them was away. One week I couldn't do, and then the next week the other one was away. 
Staff shortages have led to a serious deterioration in standards in prisons (HM Chief Inspector of Prisons, 2017) and the subsequent management and support of bereaved prisoners.

\section{The dangers of normalising grief}

Within the prison setting it seemed that prison officials found it difficult to distinguish between what constituted normal and abnormal grief. Unless a stage is reached whereby prisoners are at serious risk of self-harm or suicide, the protocol is such that the Mental Health team and some other departments regarded all other bereavement reactions as normal. The Probation workers' understanding was that inmates could only be referred on for Cruse Bereavement Care support if they had been bereaved longer than one year:

Theresa (Probation): That's the [local] rules in here. Up until that stage all they say is, "... what they're going through is normal grief." ... if they had that rule in the community then l'd think, 'Okay, that's the rule.' But why are prisons different? ... it is very difficult to talk to someone who's put their heart on the table about how they're struggling with it, to say, "Give it another four months and l'll refer you."

The Cruse Bereavement Care volunteer made herself available for half a day a week to see prisoners via the Chaplaincy, with demand often exceeding supply. The Cruse Standard for Access, Referral, Assessment and Allocation (2014) does not include a specified time restriction as it recognises death by suicide and other sudden and traumatic deaths can benefit from an early intervention to prevent a more complex grief reaction. However, service constraints in the form of lengthy waiting lists do result in Cruse also having to delay support being provided in some parts of England, Wales and Northern Ireland (Cruse Bereavement Care, 2014). Cruse Scotland sees clients in the community after six months (Newsom et al, 2019). Hospices provide immediate support if needed, but commonly support is offered two-three months post-death (Allen et al, 2017). Prison time cannot be equated to the manner in which time is conceived in the community (Cohen and Taylor, 1972; Crewe et al, 2020) with additional stressors such as shock and anxiety being felt due to recognition of this sharp distinction (Medlicott, 1999). Incarceration can result in time frequently appearing to take on a cyclical rather than a linear form, with the act of doing time being inextricably connected to self-perceptions of vulnerability and a changed identity upon entry to the institution (Medlicott, 1999). Due to the lack of diversions, time spent in prison is regarded as hard time (Scarce, 2011) resulting in prisoners ultimately trying to survive dead time (Wahidin, 2005). Disturbingly, the nature of imprisonment and skewed perceptions of time 
may normalise complex grief reactions to the extent that the regime becomes inured and, arguably, desensitised towards them.

\section{Conclusion}

This article has identified how institutional processes can enable and disable the course of grief experienced in prison. It recognises policies and procedures which currently fail to take account of the wider implications on the needs and sensibilities (Crawley, 2005) of bereaved prisoners. One key finding was that the general structure of the grieving patterns experienced in prison may be markedly different to grieving patterns found in society. The prisoner participants experienced difficulty in cognitively accepting the reality of news of a death due to the psychosocial effects of imprisonment and their physical removal from society. This caused a protracted period of numbness, potentially leading to blocked or delayed grief. We have drawn attention to unintentional harm produced due to prison protocol, for example, when verifying information, receiving bad news, attempting to visit dying relatives and attend funerals, and the limited support currently in place to process an excessive grief reaction, healthily. The findings support Hendry's (2009) assertions that regime issues and factors associated with masculinity and culture strongly impact on the ability to process grief, with prisoners using aggressiveness to mask vulnerability. Despite the institution unconsciously inflicting additional grief-related stress, there were examples reported on a micro-level of impactful gestures and empathic concern shown by chaplains, prison staff, peers and volunteers. However, they felt frustrated through constrained capacity to do more. Institutional neglect had the potential to amplify cumulative loss (Vaswani, 2018); a significant feature of many of the men's lives who participated in the study.

Furthermore, the findings support Read and Santatzoglou (2018), who argue that disenfranchised grief is a common occurrence among prisoners. Institutional thoughtlessness (Crawley, 2005; Crawley and Sparks, 2005a, $2005 \mathrm{~b}$ ) and the impact of hidden injuries generated by the regime and environment (Crawley and Sparks, 2005b), can contribute to lack of trust in the institution. This affects the level of support a prisoner believes he can expect from the institution, which may result in him displaying the only degree of agency he can - maladaptive and avoidant coping.

In conclusion, far greater understanding is needed of this marginalised group which, arguably, could be living with one of the greatest collective concentrations of unprocessed grief within society. Greater links need to be forged between the sociology of death and criminology (Allen, 2007). The criminal justice system should consider developing a national strategy for 
bereaved prisoners comprising policies and practices which are sensitive to this discrete group of grievers. Prison can provide a unique opportunity for prisoners to deal with bereavement which has remained unprocessed (Vaswani, 2014). However, approaches need to consider issues of trust, the timeliness of support, the impact of the regime, environment and culture. Parity is urgently needed with the free world in promoting healthier grief adjustment, despite the pains of this being so keenly felt.

\section{Limitations}

The demographics of HMP North of England prisoners are not representative of the broader prison population, including young offenders and females. The single site study relied upon interpretation of policies and practices at a local level. The sample may have been biased towards men who had a negative experience. Also, the men who were in complete avoidance of their grief and those finding the topic too emotive, would not have voluntarily chosen to participate.

\section{References}

Aday R and Wahidin A (2016) Older Prisoners' Experiences of Death, Dying and Grief Behind Bars. The Howard Journal, 55(3): 312-327.

Aein F and Delaram M (2014) Giving Bad News: A Qualitative Research Exploration. Iranian Red Crescent Medical Journal, 16(6). Available at: https:// www.ncbi.nlm.nih.gov/pmc/articles/PMC4102999/ (accessed: 26 August 2019).

Allen C (2007) The poverty of death: social class, urban deprivation, and the criminological consequences of sequestration of death. Mortality, 12(1): 79-93.

Allen K, Buckle R, Oakes S, Roberts J, Smith S et al (2017) Guidelines for Bereavement Support. Cheshire \& Merseyside Palliative \& End of Life Care Strategic Clinical Network. Available at: https://www.nwcscnsenate.nhs.uk/files/ 9115/1497/8854/Guidelines for Bereavement Support November 2017.pdf (accessed: 22 December 2019).

Arnold H, Liebling A and Tait S (2007) Prison officers and prison culture. In: Jewkes Y (ed) Handbook on Prisons. Abingdon, Oxon: Willan Publishing, pp. 471-495.

Auschra C (2018) Barriers to the Integration of Care in Inter-Organisational Settings: A Literature Review. International Journal of Integrated Care, 18(1).

Available at: https://ijic.ubiquitypress.com/articles/10.5334/ijic.3068/ (accessed: 26 August 2019).

Bottoms AE (1999) Interpersonal Violence and Social Order in Prisons. In, 
Tonry $\mathrm{M}$ and Petersilia J (eds), Crime and Justice: A review of research. Chicago, IL: University of Chicago Press, pp.205-281.

Charmaz K (2014) Grounded Theory in Global Perspective: Reviews by International Researchers. Qualitative Inquiry, 20(9): 1074-1084.

Chu C, Anderson R, White N and Stone P (2020) Prognosticating for Adult Patients with Advanced Incurable Cancer: a Needed Oncologist Skill. Current Treatment Options in Oncology, 21:5. DOI 10.1007/s11864-019-0698-2.

Cohen S and Taylor L (1972) Psychological Survival: The Experience of Longterm Imprisonment. Harmondsworth: Penguin.

Corcoran M (2018) Bereavement work in the criminal justice system. In: Read S, Santatzoglou S and Wrigley A (eds) Loss, Dying and Bereavement in the Criminal Justice System. London: Routledge, pp.86-95.

Coyle A and Fair H (2018) A Human Rights Approach to Prison Management ( $3^{\text {rd }}$ edn). London: Institute for Criminal Policy Research.

Crawley E (2005) Institutional Thoughtlessness in Prisons and Its Impacts on the Day-to-Day Prison Lives of Elderly Men. Journal of Contemporary Criminal Justice, 21(4): 350-363.

Crawley E and Sparks R (2005a) Older men in prison: survival, coping and identity. In: Liebling A and Maruna S (eds) The Effects of Imprisonment. Cullompton: Willan Publishing, pp.343-365.

Crawley E and Sparks R (2005b) Hidden injuries? Researching the experiences of older men in English prisons. Howard Journal of Criminal Justice, 44: 345-356.

Creswell JW and Poth CN (2018) Qualitative Inquiry and Research Design (4 ${ }^{\text {th }}$ edn). London: Sage.

Crewe B (2012) Prison culture and the prisoner society. In: Crewe B and Bennett J (eds) The Prisoner. London: Routledge, pp.27-39.

Crewe B (2016) The sociology of imprisonment. In: Jewkes $\mathrm{Y}$, Bennett $\mathrm{J}$ and Crewe B (eds) Handbook on Prisons. London: Routledge, pp.77-100.

Crewe B, Hulley S and Wright S (2020) Life Imprisonment from Young Adulthood: Time, Identity and Adaptation. London: Palgrave Macmillan.

Cruse Bereavement Care (2014) Standard for Access, Referral, Assessment and Allocation. Available at: https://intranet.cruse.org.uk/content/standardaccess-referral-assessment-and-allocation (accessed 26 August 2019). 
Doka KJ (1989) Disenfranchised grief: recognising hidden sorrow. Lexington, MA: Lexington Books.

Doka KJ (2002) The role of ritual in the treatment of disenfranchised grief. In: Doka KJ (ed) Disenfranchised Grief: New directions, challenges, and strategies for practice. Illinois, US: Research Press.

Durcan G (2008) From the inside: Experiences of prison mental health care. London: Sainsbury Centre for Mental Health.

Ferszt GG (2002) Grief Experiences of Women in Prison following the Death of a Loved One. IIIness, Crisis \& Loss, 10(3): 242-254.

Finlay IG and Jones NK (2000) Unresolved grief in young offenders in prison. British Journal of General Practice, 50: 569-570.

Friestad C (2010) Socio-economic status and health in a marginalised group: the role of subjective social status among prison inmates. European Journal of Public Health, 20(6): 653-658.

Glaser BG and Strauss AL (1967) The Discovery of Grounded Theory: Strategies for qualitative research. New York: Aldine.

Gold Standards Framework Centre (2011) The GSF Prognostic Indicator Guidance. Royal College of General Practitioners. Available at: http:// www.goldstandardsframework.org.uk/cd-content/uploads/files/General\%20Files/ Prognostic\%20Indicator\%20Guidance\%20October\%202011.pdf (accessed 22 December 2019).

Gov.UK (2018) The General Data Protection Regulation (GDPR). Available at: https://www.legislation.gov.uk/ukdsi/2018/9780111165782/pdfs/

ukdsiem_97801 11165782 en.pdf (accessed: 26 August 2019).

Gov.UK (2019) Prison population figures: 2019. Available at: https:// www.gov.uk/government/statistics/prison-population-figures-2019 (accessed 4 October 2019).

Harner HM, Hentz PM and Evangelista MC (2011) Grief Interrupted: The Experience of Loss Among Incarcerated Women. Qualitative Health Research, 21(4): 454-464.

Harris T (2015) The Harris Review: Changing Prisons, Saving Lives. Report of the Independent Review into Self-inflicted Deaths in Custody of 18-24 year olds. London: HMSO.

Hendry C (2009) Incarceration and the tasks of grief: A narrative review. 
Journal of Advanced Nursing, 65: 270-278.

HM Chief Inspector of Prisons (2017) HM Chief Inspector of Prisons for England and Wales. Annual Report 2016-17. Available at: https://

assets.publishing.service.gov.uk/government/uploads/system/uploads/att achment_data/file/629719/hmip-annual-report-2016-17.pdf (accessed: 26 August 2019).

Holmes TH and Rahe RH (1967) The Social Readjustment Rating Scale. Journal of Psychosomatic Research, 11: 213-218.

Jewkes Y (2005) Men Behind Bars: "Doing" Masculinity as an Adaptation to Imprisonment. Men and Masculinities, 8(1): 44-63.

Kristensen P, Weisaeth I and Heir T (2012) Bereavement and mental health after sudden and violent losses: A review. Psychiatry, 75: 76-97.

Leach RM, Burgess T and Holmwood C (2008) Could recidivism in prisoners be linked to traumatic grief? A review of the evidence. International Journal of Prisoner Health, 4(2), 104-119.

Lee SA (2015) The Persistent Complex Bereavement Inventory: A Measure Based on the DSM-5. Death Studies, 39(7): 399-410.

Lichtenthal WG, Sweeney CR, Roberts KE, Corner GW, Donovan LA, Prigerson HG and Wiener L (2015) Bereavement Follow-Up After the Death of a Child as a Standard of Care in Pediatric Oncology. Pediatric Blood and Cancer, 62(5): 834-869.

Liebling A and Ludlow A (2016) Suicide, distress and the quality of prison life. In: Jewkes Y, Bennett J and Crewe B (eds) Handbook on Prisons ( $2^{\text {nd }}$ edn). London: Routledge, pp.224-245.

Lundorff M, Holmgren $\mathrm{H}$, Zachariae R, Farver-Vestergaard I and O'Connor M (2017) Prevalence of prolonged grief disorder in adult bereavement: A systematic review and meta-analysis. Journal of Affective Disorders, 212: 138-149.

Medlicott D (1999) Surviving in the Time Machine: Suicidal Prisoners and the Pains of Prison Time. Time \& Society, 8(2): 211-230.

MoJ (2019) Release on temporary licence. Available at: https://www.gov.uk/ government/publications/release-on-temporary-licence (accessed: 14 March 2020).

Newsom C, Schut H, Stroebe MS, Wilson S, Birrell J et al (2017) Effectiveness of bereavement counselling through a community-based organization: $A$ 
naturalistic, controlled trial. Clinical Psychology \& Psychotherapy, 24(6): $01512-01523$.

Newsom C, Stroebe MS, Schut H, Wilson S, Birrell J et al (2019) Communitybased counseling reaches and helps bereaved people living in low-income households. Psychotherapy Research, 29(4): 479-491.

Nielsen MK, Neergaard MA, Jensen AB, Vedsted P, Bro F et al (2017) Predictors of complicated grief and depression in bereaved caregivers: a nationwide prospective cohort study. Journal of Pain and Symptom Management, 53(3): 540-550.

NOMS (2015) PSI 33/2015 Funeral Escorts/Visits to Dying Relatives. Available at: www.justice.gov.uk/offenders/psis (accessed: 27 August 2019).

Nugent B and Schinkel M (2016) The pains of desistance. Criminology and Criminal Justice, 16(5): 568-584.

Olson MJ and McEwen MA (2004) Grief counselling groups in a mediumsecurity prison. The Journal for Specialists in Group Work, 29(2): 225-236.

Parkes CM (2006) Love and Loss. The Roots of Grief and its Complications. London: Routledge.

Peacock M, Turner M and Varey S (2018) 'We Call it Jail Craft': The Erosion of the Protective Discourses Drawn on by Prison Officers Dealing with Ageing and Dying Prisoners in the Neoliberal, Carceral System. Sociology, 52(6): 1152-1168.

Read S and Santatzoglou S (2018) Death, social losses and the continuum of disenfranchised grief for prisoners. In: Read S, Santatzoglou S and Wrigley A (eds) Loss, Dying and Bereavement in the Criminal Justice System. London: Routledge, pp.13-21.

Ricciardelli R, Maier K and Hannah-Moffat K (2015) Strategic masculinities: Vulnerabilities, risk and the production of prison masculinities. Theoretical Criminology, 19(4): 491-513.

Schetky DH (1998) Mourning in Prison: Mission Impossible? J Am Acad Psychiatry Law, 26(3): 383-391.

Scott D and Codd H (2010) Controversial issues in prisons. Maidenhead, Berks: Open University Press.

Scottish Partnership for Palliative Care (2018) A Road Less Lonely: public health approaches to death, dying and bereavement. Available at: https:// www.palliativecarescotland.org.uk/content/publications/A-Road-Less-Lonely- 
WEB.pdf (accessed 21 December 2019).

Scarce R (2002) Doing Time as an Act of Survival. Symbolic Interaction, 25: 303-321.

Stroebe M and Schut H (1999) The Dual Process Model of Coping with Bereavement: Rationale and Description. Death Studies, 23(3): 197-224.

Sykes G (1958) The Society of Captives: A Study of a Maximum Security Prison. Princetown, N.J.: Princetown University Press.

Ugelvik T (2014) Power and Resistance in Prison: Doing Time, Doing Freedom. Basingstoke, Hants: Palgrave Macmillan.

Valentine C, Bauld L and Walter T (2016) Bereavement following substance misuse: a disenfranchised grief. Omega, 72(4): 283-301.

Vaswani N (2014) The Ripples of Death: Exploring the Bereavement Experiences and Mental Health of Young Men in Custody. The Howard Journal of Criminal Justice, 53(4): 341-359.

Vaswani N (2015) A catalogue of losses: Implications for the care and reintegration of young men in custody. Prison Service Journal, 220: 26-35.

Vaswani N (2018) Beyond loss of liberty. In: Read S, Santatzoglou S and Wrigley A (eds) Loss, Dying and Bereavement in the Criminal Justice System. London: Routledge, pp.177-187.

Wahidin A (2006) Time and the Prison Experience. Sociological Research Online. Available at: https://doi.org/10.5153/sro.1245 (accessed 15 March 2020).

Weaver B and McNeill F (2014) Lifelines: Desistance, social relations, and reciprocity. Criminal Justice and Behavior 42(1): 95-107.

Williams BA, Sudore RL, Greifinger R and Morrison RS (2011) Balancing Punishment and Compassion for Seriously III Prisoners. Annals of Internal Medicine, 155(2): 122-126.

Wright AA, Zhang B, Ray A, ... Maciejewski PK and Prigerson HG (2008) Associations Between End-of-Life Discussions, Patient Mental Health, Medical Care Near Death, and Caregiver Bereavement Adjustment. JAMA, 300(14): 1665-1673.

Yeaworth RC, York J, Hussey MA, Ingle ME and Goodwin T (1980) The development of an adolescent life change event scale. Adolescence, 15(57): 91-98. 